\title{
Occurrence of Acute Respiratory Tract Infections among Children Under Five Years Attending Kinango Sub- County Hospital, Kenya
}

\author{
Betty Muriithi ${ }^{1,2 *}$, Simon Karanja ${ }^{1}$, Mohamed \\ Karama $^{3}$, Collins Okoyo ${ }^{4}$, Morris Ndemwa ${ }^{2}$, \\ Yoshio Ichinose $^{2}$ and Satoshi Kaneko ${ }^{2}$ \\ ${ }^{1}$ School of Public Health, J omo Kenyatta University of \\ Agriculture and Technology, Nairobi, Kenya \\ ${ }^{2}$ Nagasaki University Institute of Tropical Medicine- \\ Kenya Medical Research Institute Project, Nairobi, Kenya \\ 3Umma University, Kajiado, Kenya \\ ${ }^{4}$ Eastern and Southern Africa Centre of International \\ Parasite Control, Kenya Medical Research Institute, \\ Nairobi, Kenya \\ *Corresponding author: Betty Muriithi, Nagasaki \\ University, Institute of Tropical Medicine, Kenya Medical \\ Research Institute Project, Nairobi, Kenya
}

Received: J une 08, 2021; Accepted: J uly 16, 2021; Published: July 23, 2021

\begin{abstract}
Objective: To examine occurrence of Acute Respiratory tract Infections (ARIs) and determine factors associated with ARIs among children under five years attending Kinango Sub-County Hospital.

Methods: A cross-sectional survey was conducted among mother-child aged between 0-59 month's pairs attending outpatient care. Participants were recruited using systematic sampling method. Data was collected using an interviewer-administered structured questionnaire. Descriptive statistics were used to summarize child, parental and environmental characteristics. Factors associated with ARIs were established using binary logistic regression analysis. Odds Ratio (OR), at $95 \%$ Confidence Interval $(\mathrm{Cl})$ and $p<0.05$ significant level was used to describe an association between covariates and the outcome variable. Independent factors associated with occurrence of ARIS were determined by stepwise logistic regression.
\end{abstract}

Results: 385 children participated in this study. 228 children $(59.2 \%)$ presented with ARIs, of which $90.8 \%$ were due to acute upper respiratory tract infections. 9.2\% of the cases were due to pneumonia. Female gender aOR 3.39 [1.21-9.46], stunting aOR 3.62 [1.04-12.61], high parity aOR 11.45 [2.38-55.09], low maternal education aOR 3.54 [1.10-11.32] and recent hospitalization aOR 8.19 [1.75-38.43] increased the odds of occurrence of an ARI while normal birth weight aOR0.06 [0.01-0.62] was protective of ARIs.

Conclusion: A high prevalence of ARIs among children aged below five years was observed in this study, associated with gender, stunting, parity, maternal education, birth weight and recurring hospitalization. Improvements in literacy levels, child nutrition and maternal and child health at large could help to reduce morbidity due to ARIs in this population.

Keywords: Prevalence; Children under five years; Acute respiratory tract infections

\section{Introduction}

Acute Respiratory Tract Infections (ARIs) are infections of the respiratory tract of ranging severity that affect both upper and lower respiratory structures, and related organs [1]. They are among the most common causes of morbidity and mortality among children under the age of five years. They account for up to $50 \%$ of all diseases that children under five years encounter [2] and a third of underfives deaths in developing countries [3,4]. According to GBD 2017, mortalities due to acute lower respiratory tract infections only were 118.9 per 100,000 children under five years globally, representing $15 \%$ of all under-fives deaths [5]. Over half of all diagnosis among children presenting with ARI symptoms are usually due to acute upper respiratory tract infections [6,7]. A child can experience up to eight episodes of ARIs of varying severity in a year [8-10].

Although ARIs are common among both children and adults, universal treatment is still lacking due to the nature of their causative agents and diagnostic uncertainty. Symptoms of common infections such as the common cold typically clear in one to two weeks but the symptoms can be quite distressing to both the child and caregiver. Moreover, the infection can spread to other parts of the body resulting to more serious clinical disease and even fatality. Respiratory viruses have been shown to have neuroinvasive capacity [11] that results to various types of encephalopathy, alongside other systemic effects due to extension of microbial toxins, inflammation and reduced lung function [12]. ARIs are also a common reason for administration of antibiotics. Approximately $33 \%$ of consultations for a child with an upper respiratory tract infection specifically ends up with an antibiotic prescription [13]. Such irrational administration of antibiotics is steadily yielding resistance to convectional antibiotics, reducing therapeutic options for management of bacterial infections $[13,14]$.

Given the nature of childhood ARIs, prevention and control present more viable options for management of ARIs. Several risk factors for ARIs have been postulated [15,16], that modulate occurrence of ARIs, although these differ widely. Proper understanding of the drivers of occurrence of ARIs in particular settings is therefore necessary for
Austin J Public Health Epidemiol - Volume 8 Issue 3 - 2021 ISSN : 2381-9014 | www.austinpublishing group.com Muriithi et al. @ All rights are reserved
Citation: Murithi B, Karanja S, Karama M, Okoyo C, Ndemwa M, Ichinose Y, et al. Occurrence of Acute Respiratory Tract Infections among Children Under Five Years Attending Kinango Sub-County Hospital, Kenya. Austin J Public Health Epidemiol. 2021; 8(3): 1105 


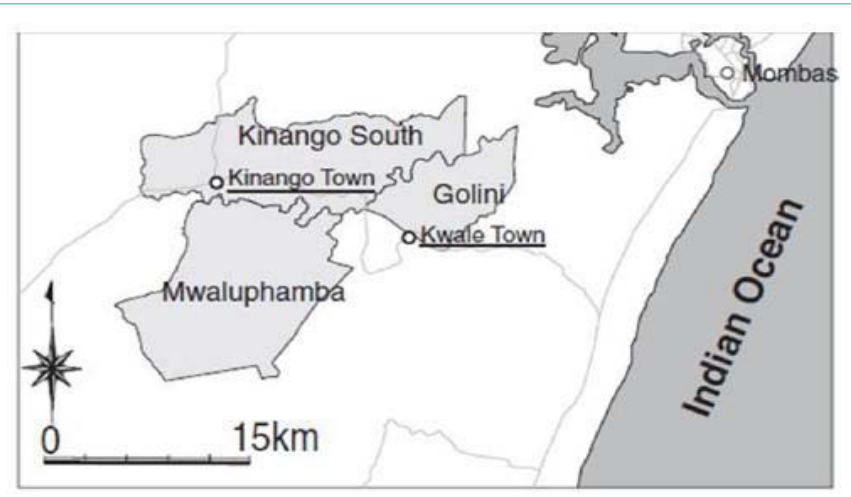

Figure 1: Study site.

development of appropriate prevention and control algorithms. The aim of this study was to examine occurrence of ARIs among children aged below five years attending Kinango Sub-County hospital and determinants of their occurrence.

\section{Methods}

\section{Study site}

The study was conducted in Kinango Sub-County Hospital, located in Kinango town within Kinango Sub-County in Kwale County, Kenya (Figure 1). The hospital is a level 4 facility with a 94bed capacity. It has a dedicated maternal and child health clinic, and an outpatient department that serves both adults and children. The hospital's community linkage is well developed, with the community health volunteers actively involved in linking the community to primary care. The hospital's catchment area covers both rural and semi-urban settlements, with varying levels of access by the community.

Kwale County is mostly sparsely populated with a poverty index of $41.8 \%$ [17]. It is served by one level four hospital, two level three hospitals and thirty-four level two public health facilities. The average distance to the nearest health facility is about seven kilometers [18].

\section{Study design and sample size calculation}

A cross-sectional hospital-based study was conducted. Sample size was calculated using Cochrane formula [19], with a sampling error of $5 \%$ at $95 \%$ confidence interval assuming a prevalence of $50 \%$, yielding a minimum sample of 385 .

\section{Study population}

Study subjects were children aged below five years and their mothers. Systematic sampling was used to randomly select study participants. About 800 children aged below five years are usually seen at the outpatient clinic per month. Data was collected from November 2017 to January 2018, during which approximately 2400 children aged below five years were treated. Using a sampling interval of six, every $6^{\text {th }}$ mother-child pair was selected to participate in the study starting from a random point until the sample size was achieved. Children whose mothers consented for their participation were included in the study. Children who were accompanied by caregivers were excluded as well as children whose mothers declined consent.

\section{Study procedure}

Recruitment of study participants was conducted during routine outpatient care. Objectives and procedure of the study were explained to the mother-child dyads at the outpatient clinic before consultation. Based on description by WHO [20], an ARI was defined as any acute episode of runny nose, cough, ear discharge, pain or itch, sore throat or hoarseness of voice, difficult or fast breathing with or without fever, or chest in drawing. Upon consultation, cases were classified using the Integrated Management of Childhood Illness (IMCI) criteria [21]. The diagnosis of children who were not suffering from an ARI was also clearly recorded on the health cards. Recruitment of study participants was conducted at the records department after going through the consultation process. Every $6^{\text {th }}$ mother-child pair was requested to participate in the study. In case a selected subject declined consent, the next mother-child pair was requested to participate. The consent form was read and explained to those who agreed to participate in the study after which they were requested to sign the consent document.

\section{Data collection}

Following consenting, data collection was conducted using an interviewer-administered structured questionnaire. Presence or absence of an ARI was recorded from the patient's health card. Birth and immunization details of the child were obtained from the maternal and child health booklet where possible or parental recall. The child's weight and height were then taken for computation of Z-scores. The height of infants (0-23 months) was measured in recumbent position using a wooden height board. Heights of children aged above two years were measured in standing position using a vertical height board. The child was placed on board base, to stand in in upright position with head held upright, and back of the head, back and heels against the board. Children aged 0-6 months were weighed using an electronic scale in lying position. Older children who could not stand were weighed in sitting position while those who could stand were weighed in standing position, all lightly dressed.

\section{Statistical analysis}

Data was entered into Microsoft access (2016) and exported to STATA Version 14 [22] for analysis. Socioeconomic indicators were summarized using Principal Component Analysis (PCA). Wealth quintiles were then generated and grouped into low, middle and high socioeconomic status. Descriptive and summary statistics were used to summarize child, parental and environmental characteristics in order to describe the study population and calculate the prevalence of ARIs. Factors associated with occurrence of ARIs were established using binary logistic regression. Association was measured using odds ratio at 0.05 significant level and $95 \%$ confidence interval. Multivariable regression model was constructed by stepwise estimation, using backward selection. Variables with a P-value greater than or equal to 0.2 were removed sequentially. The model was adjusted for age of the children, gender, birthweight, immunization status, breastfeeding status, underweight, stunting, parental characteristics, exposure to school-going children, contact with an infected person in the past two weeks, previous hospitalization, household density and socioeconomic status.

\section{Results}

Out of the 385 children who participated in the study, 228 
Table 1: Diagnosis observed among study children.

\begin{tabular}{|l|c|c|}
\hline \multicolumn{1}{|c|}{ Diagnosis } & Number of Children & $\%$ \\
\hline Acute respiratory infection & 216 & 56.1 \\
\hline Acute respiratory tract infection with co-infection & 12 & 3.1 \\
\hline Acute febrile illness & 53 & 13.8 \\
\hline Dermatological conditions & 40 & 10.4 \\
\hline Gastrointestinal infection & 19 & 4.9 \\
\hline Malaria & 4 & 1 \\
\hline
\end{tabular}

(59.2\%) presented with ARIs. 5\% were co-infected mostly with gastrointestinal and dermatological conditions. Acute febrile illness and dermatological conditions were frequently reported as shown on Table 1. According to IMCI guidelines, 207 (90.8\%) children had ARIs and 21 (9.2\%) had pneumonia. No cases of severe pneumonia were observed.

\section{Demographic characteristics of study children}

Of the study sample, 192 (49.9\%) were male. Mean age was 22.14 \pm 14.7 months. Majority of the participants; 237 (61.6\%) were aged below two years of whom $58(15.1 \%)$ were aged below six months. Only 95 (24.7\%) children were born at home. Average breastfeeding duration was $20.1 \pm 5.1$ months. Children who were fully immunized as per schedule were $277(72 \%)$ as shown in Table 1. Prevalence of underweight, stunting and wasting was $15.8 \%, 26.3 \%$ and $11.4 \%$ respectively.

Table 2: Demographic characteristics of study children and association between ARIs and children's demographic characteristics.

\begin{tabular}{|c|c|c|c|c|c|c|}
\hline Characteristic & No. of Participants (\%) & No. of Cases (\%) & OR $(95 \% \mathrm{Cl})$ & P-value & Adjusted OR (95\% Cl) & P-value \\
\hline \multicolumn{7}{|l|}{ Age (Months) } \\
\hline $0-6$ & $58(15.1)$ & $33(56.9)$ & $1.06(0.57-1.96)$ & 0.846 & & \\
\hline $7-12$ & $67(17.4)$ & $42(62.9)$ & $1.35(0.74-2.44)$ & 0.318 & & \\
\hline $13-24$ & $112(29.1)$ & $71(63.4)$ & $1.39(0.84-2.30)$ & 0.196 & & \\
\hline $25-59$ & $148(38.4)$ & $82(55.4)$ & Reference & & & \\
\hline \multicolumn{7}{|l|}{ Gender } \\
\hline Male & $192(49.9)$ & $103(53.6)$ & Reference & & Reference & \\
\hline Female & $193(50.1)$ & $125(64.8)$ & $1.59(1.05-2.39)$ & 0.027 & $3.39(1.21-9.46)$ & 0.02 \\
\hline \multicolumn{7}{|l|}{ Birth Weight } \\
\hline Low & $25(8.9)$ & $15(60.0)$ & Reference & & Reference & \\
\hline Normal & $256(91.1)$ & $151(59.0)$ & $0.96(0.41-2.22)$ & 0.921 & $0.06(0.01-0.61)$ & 0.018 \\
\hline \multicolumn{7}{|l|}{ Place of Birth } \\
\hline Home & $95(24.7)$ & $54(56.8)$ & Reference & & & \\
\hline Hospital & $290(75.3)$ & $174(60.0)$ & $1.14(0.71-1.82)$ & 0.59 & & \\
\hline \multicolumn{7}{|l|}{ Breast Feeding Status } \\
\hline Supplemented & $61(18.3)$ & $37(60.7)$ & Reference & & & \\
\hline Exclusive & $272(81.7)$ & $161(59.2)$ & $0.94(0.53-1.66)$ & 0.833 & & \\
\hline \multicolumn{7}{|l|}{ Breast Feeding Duration } \\
\hline 0-12 months & $18(9.6)$ & $11(61.1)$ & $2.36(0.31-17.85)$ & 0.407 & & \\
\hline 13-24 months & $165(87.8)$ & $93(56.4)$ & $1.94(0.31-11.90)$ & 0.475 & & \\
\hline 25-36 months & $5(2.7)$ & $2(40.0)$ & Reference & & & \\
\hline \multicolumn{7}{|l|}{ Immunization Status } \\
\hline Incomplete & $21(5.4)$ & $11(52.4)$ & $0.70(0.29-1.71)$ & 0.438 & $0.06(0.00-1.28)$ & 0.071 \\
\hline \multicolumn{7}{|l|}{ Weight for Age } \\
\hline Normal & $324(84.2)$ & $194(59.9)$ & Reference & & & \\
\hline Underweight & $61(15.8)$ & $34(55.7)$ & $0.84(0.48-1.46)$ & 0.547 & & \\
\hline \multicolumn{7}{|l|}{ Height for Age } \\
\hline Normal & $284(73.8)$ & $166(58.4)$ & Reference & & & \\
\hline Stunted & $101(26.3)$ & $62(61.4)$ & $1.13(0.71-1.80)$ & 0.606 & $3.63(1.04-12.61)$ & 0.043 \\
\hline \multicolumn{7}{|l|}{ Height for Weight } \\
\hline Normal & $341(88.6)$ & $209(61.3)$ & Reference & & & \\
\hline Wasted & $44(11.4)$ & $19(43.2)$ & $0.48(0.25-0.91)$ & 0.024 & & \\
\hline
\end{tabular}


Table 3: Environmental characteristics of study participants and association between ARIs and children's environmental characteristics.

\begin{tabular}{|c|c|c|c|c|c|c|}
\hline Characteristic & $\begin{array}{c}\text { No participants } \\
(\%)\end{array}$ & Prevalence & $\begin{array}{c}\text { Univariable analysis OR } \\
(95 \% \mathrm{Cl})\end{array}$ & P-value & $\begin{array}{c}\text { Multivariable analysis aOR } \\
(95 \% \mathrm{Cl})\end{array}$ & P-value \\
\hline \multicolumn{7}{|l|}{ Household density } \\
\hline $2-4$ & $171(44.4)$ & $98(57.3)$ & Reference & & & \\
\hline $5-7$ & $156(40.5)$ & $95(60.9)$ & $1.16(0.75-1.80)$ & 0.51 & & \\
\hline$\geq 8$ & $58(15.1)$ & $35(60.3)$ & $1.14(0.62-2.08)$ & 0.686 & & \\
\hline \multicolumn{7}{|l|}{ Number of rooms } \\
\hline 1 & $23(6.0)$ & $13(56.5)$ & Reference & & & \\
\hline 2 & $193(50.1)$ & $113(58.5)$ & $1.09(0.45-2.60)$ & 0.852 & & \\
\hline$\geq 3$ & $169(43.9)$ & $102(60.4)$ & $1.17(0.48-2.82)$ & 0.725 & $2.34(0.76-7.20)$ & 0.139 \\
\hline \multicolumn{7}{|c|}{$\begin{array}{l}\text { History of contact with an infected } \\
\text { person }\end{array}$} \\
\hline Had contact & $166(43.1)$ & $99(59.6)$ & Reference & & & \\
\hline \multicolumn{7}{|l|}{ School-going sibling } \\
\hline Yes & $260(67.5)$ & $164(63.1)$ & Reference & & & \\
\hline No & $125(32.5)$ & $64(51.2)$ & $0.61(0.40-0.95)$ & 0.027 & & \\
\hline \multicolumn{7}{|l|}{$\begin{array}{l}\text { Hospitalization within the past } 3 \\
\text { months }\end{array}$} \\
\hline No & $306(79.5)$ & $180(58.8)$ & Reference & & & \\
\hline Yes & $79(20.5)$ & $48(60.8)$ & $1.08(0.65-1.79)$ & 0.755 & $8.19(1.74-38.43)$ & 0.008 \\
\hline \multicolumn{7}{|l|}{ Cause of hospitalization } \\
\hline Respiratory infection related & $41(51.9)$ & $26(63.4)$ & $1.26(0.51-3.11)$ & 0.616 & & \\
\hline Not respiratory infection related & $38(48.1)$ & $22(57.9)$ & Reference & & & \\
\hline \multicolumn{7}{|l|}{ Exposure to cigarette smoke } \\
\hline No & $238(61.8)$ & $138(58.0)$ & $0.87(0.57-1.33)$ & 0.53 & & \\
\hline \multicolumn{7}{|l|}{ Socioeconomic status } \\
\hline Low & $132(35.9)$ & $79(59.8)$ & Reference & & & \\
\hline Middle & $116(31.5)$ & $69(59.5)$ & $0.98(0.59-1.63)$ & 0.953 & $4.23(0.90-19.96)$ & 0.068 \\
\hline High & $120(32.6)$ & $69(57.5)$ & $0.91(0.54-1.50)$ & 0.705 & $3.01(0.68-13.23)$ & 0.145 \\
\hline
\end{tabular}

\section{Demographic characteristics of parents of study children}

Average maternal age was $26 \pm 6.1$ years. Age ranged from 17 to 47 years. Mothers who had primary level of education were 182 (47.3\%). Only $47(12.2 \%)$ of the mothers had attended secondary education and above. Most mothers; 252 (65.5\%) were unemployed while 310 (86.4\%) fathers were in various forms of employment as shown on Table 2.

\section{Environmental characteristics of study participants}

Majority of the children, $288(74.8 \%)$ lived in mud walled houses. Most of the houses; 254 (66.0\%) had iron sheet roofing and 298 (77.4\%) houses had earthen floor material. Firewood (80\%) and charcoal (13\%) were the most common sources of cooking energy while kerosene $(57.7 \%)$ and solar $(32.0 \%)$ were the most common sources of lighting energy.

\section{Univariable analysis of factors associated with ARIs}

As shown in Table 1, female children were significantly more likely (OR 1.59; 95\% CI: 1.05-2.39) to be infected with an ARI compared to male children. Odds of infection increased with increase in age, with children aged between 13 to 24 months presenting the highest odds of infection (OR 1.39; 95\% CI: 0.84-2.30). Breastfeeding was protective of ARIs by $6 \%$ (OR 0.94; 95\% CI: 0.53-1.66), as well as normal birth weight (OR 0.95; 95\% CI: 0.41-2.22) although not significantly. Odds of infection decreased with increasing breastfeeding duration. Immunization was generally protective of ARIs, with children who were up-to-date on the immunization schedule presenting up to $30 \%$ reduced odds of infection (OR 0.70; 95\% CI: 0.29-1.71).

The risk of getting an ARI decreased by $43 \%$ among children whose fathers were educated up to primary school (OR 0.57; 95\% CI: 0.34-0.96). Age, marital status, level of education and employment status of mothers were not statistically significant determinants of occurrence of ARIs. However, odds of infection decreased with increase in mothers' age and with increasing level of education as shown on Table 2.

Not having school going siblings was a significant protective factor too (OR 0.61; 95\% CI: 0.40-0.95). Odds of infection increased with increase in household density and number of rooms although not significantly. Absence of contact with an infected person marginally reduced the odds of infection by $3 \%$ (OR 0.97 ; $95 \%$ CI: 
Table 4: Parental socio-demographic characteristics and association between ARIs and Parental socio-demographic characteristics.

\begin{tabular}{|c|c|c|c|c|c|c|}
\hline Characteristic & No of participants (\%) & ARI Prevalence \% & OR $(95 \% \mathrm{Cl})$ & P-value & Adjusted OR (95\% Cl) & P-value \\
\hline \multicolumn{7}{|l|}{ Maternal age } \\
\hline$<20$ & $52(13.5)$ & $27(51.9)$ & Reference & & & \\
\hline $21-30$ & $249(64.7)$ & $152(61.0)$ & $1.45(0.79-2.64)$ & 0.225 & & \\
\hline$>31$ & $84(21.8)$ & 49 (58.3) & $1.30(0.65-2.60)$ & 0.465 & & \\
\hline \multicolumn{7}{|l|}{ Marital status of mother } \\
\hline Married & $359(93.3)$ & $209(58.2)$ & $0.51(0.21-1.25)$ & 0.143 & & \\
\hline Single & $26(6.7)$ & $19(73.1)$ & Reference & & & \\
\hline \multicolumn{7}{|l|}{ Education level of mother } \\
\hline No formal education & $156(40.5)$ & $90(57.7)$ & Reference & & & \\
\hline Primary education & $182(47.3)$ & $110(60.4)$ & $1.12(0.73-1.73)$ & 0.609 & $3.54(1.10-11.32)$ & 0.033 \\
\hline Secondary education and above & $47(12.2)$ & $28(59.6)$ & $1.08(0.56-2.10)$ & 0.819 & & \\
\hline \multicolumn{7}{|l|}{ Education level of father } \\
\hline No formal education & $90(25.1)$ & $58(64.4)$ & Reference & & & \\
\hline Primary education & $177(49.3)$ & $90(50.8)$ & $0.57(0.34-0.96)$ & 0.035 & $0.37(0.13-1.09)$ & 0.07 \\
\hline Secondary education and above & $92(25.6)$ & $61(66.3)$ & $1.09(0.59-2.00)$ & 0.792 & & \\
\hline \multicolumn{7}{|l|}{ Employment status of mother } \\
\hline Housewife & $52(13.5)$ & $27(51.9)$ & Reference & & & \\
\hline Unemployed & $252(65.5)$ & $155(61.5)$ & $1.48(0.81-2.70)$ & 0.201 & $5.14(0.90-29.36)$ & 0.065 \\
\hline Employed & $81(21.0)$ & $46(56.8)$ & $1.21(0.60-2.45)$ & 0.582 & $7.21(0.84-61.58)$ & 0.071 \\
\hline \multicolumn{7}{|l|}{ Employment status of father } \\
\hline Unemployed & $49(13.7)$ & $33(67.3)$ & Reference & & & \\
\hline Employed & $310(86.4)$ & $176(56.8)$ & $0.64(0.33-1.21)$ & 0.166 & & \\
\hline \multicolumn{7}{|l|}{ Parity } \\
\hline $3-4$ & $106(27.5)$ & $62(58.5)$ & $1.01(0.62-1.64)$ & 0.967 & $4.69(1.20-18.28)$ & 0.026 \\
\hline$\geq 5$ & $97(25.2)$ & $60(61.9)$ & $1.16(0.70-1.92)$ & 0.558 & $11.46(2.38-55.09)$ & 0.002 \\
\hline
\end{tabular}

0.64-1.46), as well as not having been previously hospitalized in the last three months (OR 0.86; 95\% CI: 0.50-1.46). Absence of a smoker in a household lowered the odds of infection by $13 \%$ (95\% CI: $0.57-$ 1.33) as shown on Table 3.

Housing characteristics, source of cooking and lighting energy and overall exposure of a child to wood smoke were not significantly associated with occurrence of an ARI. These factors were used to calculate socioeconomic status of participants using PCA. Computed scores were categorized onto low, middle and high socioeconomic status, which too were not significantly associated with occurrence of ARIs.

\section{Multivariable analysis}

Female children were three times more likely (aOR 3.39; 95\% CI 1.21-9.46) to be infected with an ARI compared to male children. Normal birth weight was significantly protective of ARIs, with up to 94\% (aOR 0.06; 95\% CI: 0.01-0.62) reduced odds of infection while stunting posed a three-folds increase in odds (aOR 3.62; 95\% CI: 1.0412.61) of getting and ARI as shown on Table 1. Among the parental characteristics, primary level of education among mothers increased a child's odds of getting an ARI by three times (aOR 3.54; 95\% CI: $1.10-11.32)$. High parity also significantly increased odds of infection, with having five and above children increasing odds of infection by 11 times (aOR 11.45; 95\% CI: 2.38-55.09) as shown on Table 4. Recent hospitalization significantly increased odds of getting an ARI by 8 times (aOR 8.19; 95\% CI: 1.75-38.43).

\section{Discussion}

ARIs remain an important public health problem, causing significant morbidity and mortality, and children continue to bear the highest burden of these infections. This study reported a prevalence of 59.2\%. In agreement with this finding, Muthoni \& Ngesa [9], reported an estimated ARI prevalence of 55-60 \% for Kwale County from models based on national health and demographic survey data. Additionally, a high individual risk of infection by various respiratory viruses, up to $93.4 \%$ was reported in a large household survey in rural North Coast with similar settings [23], suggesting a high likelihood of occurrence of ARIs along the larger coastal region. The high prevalence observed could also be as a result of timing of the study, since the study was conducted during a peak season for transmission of respiratory diseases. Equally high prevalence rates were observed in related studies $[16,24,25]$, highlighting a substantial burden of ARIs among children under five years in various settings.

ARI infections peaked at two years. This age group has been shown 
to be highly vulnerable to ARIs mostly due to underdevelopment of their immune system [26], coupled with incomplete development of their lungs and relatively short bronchial tree that causes an infection to spread faster [27]. Additionally, increasing contact between the child and other household members as the child grows older and decreasing protective effects of passive maternal immunity, coupled with increased contact with fomites makes them more exposed to ARIs.

This study identified female gender as a significant determinant for occurrence of ARIs. Although previous studies [1,28,29] have consistently reported a higher risk among males. Involvement of gender in development of ARIs remains relatively non-conclusive. For instance, no consistent sex differences in the burden of ARIs was observed over a period of twenty-four years, even after controlling for possible confounding factors while examining sex-specific trend of childhood ARIs in Nigeria [30]. Since perception of gender as a potential modulator of response to infection persists, it is necessary to elucidate its mechanisms and establish whether it is applicable to childhood ARIs in order to understand ARIs development in each gender.

Normal birth weight was significantly protective against ARIs in this study. Birthweight is an important modulator of child survival, growth and development [31]. Children born with low birth weight are more susceptible to respiratory infections [6] especially of the lower respiratory tract [32]. Protective effect of normal birth weight observed in this study was tentatively due to immune system sufficiency and optimal lung function conferred by normal birthweight, despite potential confounding by factors such as malnutrition and continued exposure to environmental triggers.

Childhood stunting increased the odds of getting an ARI in this study. The high prevalence of malnutrition that has been extensively reported in this population [33-35] tentatively explains this observation. Although the relationship between infections and malnutrition is mostly bidirectional [36,37], a child with underlying malnutrition lacks nutrients needed for immune activation, increasing their susceptibility to acute infections [38]. Further, the process of linear growth catch-up that could reverse stunting and its effects on immunity may be slow or impossible in this setting due to food insecurity and high burden of infectious diseases resulting in sustained stunting with sustained susceptibility to ARIs [39]. In concurrence, an association between stunting and occurrence of ARIs among children was similarly observed in a study conducted in Bangladesh [40].

Maternal education status was significantly associated with occurrence of ARIs too. Children whose mothers were educated up to primary level had significantly increased odds of getting an ARI. Moreover, odds of infection decreased with increasing level of maternal education in the unadjusted model although not significantly. Generally, a higher level of education among mothers promotes adoption of good childcare practices that reduce exposure of children to ARIs and other infections. It is also likely to improve social and environmental conditions of a household resulting in improvements in child health by modifying factors such as employment and household income. In agreement with the findings of this study, a meta-analysis of observational studies from low and middle-income countries identified low maternal education as a risk factor for mortality due to acute infections of the lower respiratory tract [41], confirming the impact of maternal education.

Hospitalization in the preceding three months significantly increased the odds of getting an ARI. Recurrent hospitalization in early childhood increases the risk of morbidity with acute respiratory infections and even asthma in a dose response manner [42]. Recurrent ARIs particularly increase the risk of subsequent respiratory infections [43]. Of the children who had been previously hospitalized in this study, 51.9\% had been hospitalized for respiratory related infections especially pneumonia and asthma, suggesting that recurrent ARIs potentially increase the risk of getting an ARI in future.

Parity was shown to affect occurrence of ARIS, with odds of getting an ARI increasing with increasing parity. High parity could have increased household density and person-to-person contact, facilitating transmission of respiratory pathogens. Moreover, this study observed an association between school-going siblings and occurrence of ARIs, who have been shown to be important introducers of respiratory pathogens in households [44], suggesting a potential risk posed by multiple siblings. High parity compromises quality of care accorded to each child too, due to increased financial and social requirements. This affects not only living conditions but also nutritional care of children especially since this population has been shown to be relatively food insecure [33], generally increasing susceptibility to infectious diseases.

An important limitation of this study is that prevalence of ARIs was captured at the hospital level hence it may not be a true reflection of the activity of ARIs in the community. A longitudinal study will illustrate the epidemiology of ARIs among under-fives better. Additionally, diagnosis was made based on clinical symptoms using IMCI guidelines. Over diagnosis or under diagnosis is possible given the limitations surrounding its application.

\section{Conclusion}

This study highlights a high burden of ARIs among children under five years. Female gender, stunting, low maternal education and high parity were significantly associated with occurrence of ARIs. Normal birth weight and absence of hospitalization in the previous three months were protective factors. This study suggests that improvements in maternal education, with increased awareness on maternal and child health could minimize morbidity due to ARIs in this population. Prevention and management of other infectious diseases is also likely to reduce the burden of ARIs and improve overall health of children. Since no intervention can singly reduce morbidity and mortality due to ARISs, modulation of core risk factors could substantially help to reduce preventable deaths.

\section{Acknowledgement}

We acknowledge the Kwale County Government for allowing us to conduct this study. We also acknowledge and appreciate Kinango sub-County hospital for supporting implementation of this study. We thank Nagasaki University Institute of Tropical Medicine, Kenya research station for supporting the study and appreciate the caregivers who participated in this survey for voluntarily participating in this study and for the time they freely put into the study. 


\section{References}

1. Pinzón-rondón ÁM, Aguilera-otalvaro $P$, Zárate-ardila $C$, Hoyos-martínez A, Pinzón-rondón ÁM, Aguilera-otalvaro P, et al. Acute respiratory infection in children from developing nations: a multi-level study. Paediatrics and International Child Health. 2016; 9047.

2. Mucia M, Salvago P, Brancato A, Cannizzaro C, Cannizzaro E, Gallina S, et al. Upper respiratory tract infections in children: from case history to management. Acta Medica Mediterranea. 2015; 31: 419-424.

3. Rudan I, Tomaskovic L, Boschi-pinto C, Campbell H \& Health C. Globa estimate of the incidence of clinical pneumonia among children under five years of age. Bulletin of the World Health Organization. 2004; 82: 895-903.

4. Abubakar A, Malik M, Pebody RG, Elkholy AA, Khan W, Bellos A, et al. Burden of acute respiratory disease of epidemic and pandemic potential in the WHO Eastern Mediterranean Region: A literature review. EMHJ. 2016; 22: $513-526$

5. Troeger C, Forouzanfar M, Rao PC, Khalil I, Brown A, Swartz S, et al Estimates of the global, regional, and national morbidity, mortality, and aetiologies of lower respiratory tract infections in 195 countries : a systematic analysis for the Global Burden of Disease Study 2015. Lancent Infectious Diseases. 2017; 17: 1133-1161.

6. Kandelaki E, Kherkheulidze M, Kavlashvili N \& Chkhaidze I. Late preterm and low birth weight - possible impact on respiratory system at age of 12 month. European Respiratory Journal. 2014; 44: P1254.

7. Kjærgaard J, Anastasaki M, Isaeva E, Akylbekov A, Nguyen NQ, Id SR, et al. Diagnosis and treatment of acute respiratory illness in children under five in primary care in low-, middle-, and high-income countries: A descriptive FRESH AIR study. PLoS ONE. 2019; 14: 1-16

8. Heikkinen T \& Järvinen A. The common cold. The Lancet. 2003; 361: 51-59.

9. Muthoni KA \& Ngesa OO. Determinants and Spatial Modeling of Acute Respiratory Infections (ARI) Among Children Less Than Five Years in Kenya. American Journal of Theoretical and Applied Statistics. 2017; 6: 123-128.

10. Alsuhaibani MA, Alkheder RS, Alwanin JO, Alharbi MM, Alrasheedi MS \& Almousa RF. Parents awareness toward antibiotics use in upper respiratory tract infection in children in Al-Qassim region, Saudi Arabia. 2019; 8: 583

11. Desforges M, Coupanec A Le, Dubeau P, Lajoie L, Dub M \& Talbot PJ. Human Coronaviruses and Other Respiratory Viruses: Underestimated Opportunistic Pathogens of the Central Nervous System? Viruses. 2019: 12: 14

12. Gaude GS. Acute respiratory infections in children: Can we prevent? Indian Journal of Health Sciences. 2016; 9: 1-4

13. Easton G \& Saxena S. Antibiotic prescribing for upper respiratory trac infections in children: how can we improve? Child Health Antibiotic prescribing for upper respiratory tract infections in children: how can we improve? London Journal of Primary Care. 2010; 3: 37-41.

14. Qiao LWX, Ai L \& Wang JZX. Isolation of antimicrobial resistant bacteria in upper respiratory tract infections of patients. 3 Biotech. 2016; 6: 1-7.

15. Akinyemi JO \& Morakinyo OM. Household environment and symptoms of childhood acute respiratory tract infections in Nigeria, 2003-2013: a decade of progress and stagnation. BMC Infectious Diseases. 2018; 18: 296.

16. Tazinya AA, Halle-ekane GE, Mbuagbaw LT, Abanda M, Atashili J \& Obama MT. Risk factors for acute respiratory infections in children under five years attending the Bamenda Regional Hospital in Cameroon. BMC Pulmonary Medicine. 2018; 18: 1-8.

17. KNBS. Exploring Kenyas Inequality: Pooling Apart or pooling together? KNBS. 2013

18. KNBS \& SID. Kwale County; Exporing Kenya's inequality. KNBS. 2013.

19. Cochrane W. Sampling techniques ( $3^{\text {rd }}$ ed.). New York: John Wiley \& Sons, Ltd. 1977.

20. WHO E. Pocket Book of Hospital Care for Children: Guidelines for the Management of Common Childhood Illnesses. WHO Press? $2^{\text {nd }}$ ed. Geneva.
2013.

21. WHO \& UNICEF. IMCI adaptation guide. WHO, Geneva. 2002.

22. StataCorp. Stata Statistical Software: Release 14. 2015

23. Munywoki PK, Koech DC, Agoti CN, Cane PA, Medley GF \& Nokes DJ. Continuous Invasion by Respiratory Viruses Observed in Rural Households during a Respiratory Syncytial Virus Seasonal Outbreak in Coastal Kenya. Clinical Infectious Diseases. 2018; 67: 1559-1567.

24. Kumar SG, Majumdar A, Kumar V, Naik BN, Selvaraj K \& Balajee K. Prevalence of acute respiratory infection among under-five children in urban and rural areas of Puducherry, India. J Nat Sc Biol Med. 2015; 6: 3-7.

25. Koirala R. Risk Factors of Acute Respiratory Infections in Children under Five Years Attending the Fishtail. J-GMC-N. 2019; 12: 74-79.

26. Madsen $\mathrm{HO}$ \& Hansen $\mathrm{CH}$. Acute Respiratory Tract Infections and MannoseBinding Lectin Insufficiency during Early Childhood. JAMA. 2001; 285: 13161321.

27. Paul SP, Wilkinson R \& Routley C. Management of respiratory tract infections in children. Nursing Research and Reviews. 2014; 4: 135-148.

28. Hemila $\mathrm{H}$. Vitamin $\mathrm{C}$ and sex differences in respiratory tract infections. Respiratory Medicine. 2008; 102: 625-626

29. Khalek EMA \& Abdel-salam DM. Acute respiratory tract infections in children under 5 years of age in Upper Egypt. Int J Community Med Public Health. 2016; 3: 1161-1166

30. Orimadegun A \& Myer L. Sex-Specific Prevalence and Trends in Acute Respiratory Infection Episodes among Children Less than 5 Years in Nigeria. Nigerian Journal of Clinical Practice. 2019; 22: 1590-1599.

31. Ibama A, Dozie I, Abanobi O, Amadi A, Nwufo C, Ibe S, et al. Low Birth Weight and Its Association with Pattern and Risk of Acute Respiratory Infection among Infants in Rivers State, Nigeria: What Can we do to Improving the Situation. Int J Clin Med Cases. 2020; 3: 1-7.

32. Martins ALO, Da Silva Fernandes Nascimento D, Schneider IJC \& SchuelterTrevisol F. Incidence of community-acquired infections of lower airways among infants. Revista Paulista de Pediatria. 2016; 34: 204-209.

33. Shinsugi C, Matsumura M, Karama M, Tanaka J \& Changoma M. Factors associated with stunting among children according to the level of food insecurity in the household: a cross-sectional study in a rural community of Southeastern Kenya. BMC Public Health. 2015; 15: 1-10.

34. Ndemwa M, Wanyua S, Kaneko S, Karama M \& Makokha A. Nutritional status and association of demographic characteristics with malnutrition among children less than 24 months in Kwale County, Kenya. Pan African Medical Journal. 2017; 28: 1-9.

35. Tanaka J, Yoshizawa K, Hirayama K, Karama M, Wanjihia V, Changoma MS, et al. Relationship between dietary patterns and stunting in preschool children: a cohort analysis from Kwale, Kenya. BMC Public Health. 2019; 173: $58-68$

36. Ginsburg AS, Izadnegahdar R, Berkley JA, Walson JL, Rollins N \& Klugman $\mathrm{KP}$. Undernutrition and pneumonia mortality. The Lancet Global Health. 2015; 3: e735-e736.

37. Morais AHDA, Aquino JDS, Silva-maia JK, Helena S, Vale DL, Leal B, et al. Nutritional status, diet and viral respiratory infections: perspectives for severe acute respiratory syndrome coronavirus 2. 2020.

38. Jones KDJ \& Berkley JA. Severe acute malnutrition and infection. Paediatrics and International Child Health. 2014; 34: S1-S29.

39. Desmond C \& Casale D. Catch-up growth in stunted children: Definitions and predictors. PLoS ONE. 2017; 12: 1-12.

40. Marufa S, Sarker AR, Sheikh N \& Akram R. Prevalence, determinants and health care- seeking behavior of childhood acute respiratory tract infections in Bangladesh. PLoS Medicine. 2019; 14: e0210433.

41. Sonego M, Pellegrin MC, Becker G \& Lazzerini M. Risk factors for mortality from Acute Lower Respiratory Infections (ALRI) in children under five years 
of age in low and middle-income countries: A systematic review and metaanalysis of observational studies. PLoS ONE. 2015; 10: 1-17.

42. Moore HC, Hall GL \& De Klerk N. Infant respiratory infections and later respiratory hospitalization in childhood. European Respiratory Journal. 2015; 46: 1334-1341.
43. Schaad UB, Esposito S \& Razi CH. Diagnosis and Management of Recurrent Respiratory Tract Infections in Children: A Practical Guide. 2016; 4.

44. Munywoki PK, Koech DC, Agoti CN, Lewa C, Cane PA, Medley GF, et al. The source of respiratory syncytial virus infection in infants: A household cohort study in rural Kenya. Journal of Infectious Diseases. 2014; 209: 1685-1692. 